\title{
Symptomatic unicuspid aortic valve
}

\author{
Gohar Jamil, ${ }^{1}$ Walaa Said Dabbas, ${ }^{2}$ Mahmuneer Khan, ${ }^{3}$ Mujgan Jamil ${ }^{4}$
}

${ }^{1}$ Tawam Hospital, Al Ain, United Arab Emirates ${ }^{2}$ Department of Medicine, Tawam Hospital, Al Ain, United Arab Emirates

${ }^{3}$ Department of Surgery, Khyber Medical College, Peshawar, Pakistan ${ }^{4}$ Imperial College, Al Ain, United Arab Emirates

Correspondence to Dr Gohar Jamil, goharjamil@gmail.com

Accepted 28 November 2015

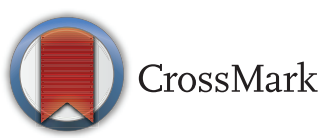

To cite: Jamil $G$ Dabbas WS, Khan M, et al BMJ Case Rep Published online: [please include Day Month Year] doi:10.1136/ bcr-2015-212922

\section{SUMMARY}

A 22-year-old man with typical angina was seeking medical attention at primary health clinics for a couple of months. Owing to his young age and the absence of coronary artery disease risk factors, he was assured of no serious problem. Proper examination at a referral centre revealed weak peripheral pulses with diminished and delayed carotid upstroke. A normal S1 with a soft S2 were audible. A 3/6 late peaking systolic murmur was best heard in the aortic area radiating to the neck. Symptomatic bicuspid aortic valve disease was suspected. Diagnosis of unicuspid aortic valve was established by transoesophageal and three-dimensional echocardiography. The valve was successfully replaced with a mechanical prosthesis. The patient remains asymptomatic at 1 year follow-up.

\section{BACKGROUND}

Chest pain in the young is usually attributed to non-cardiac causes. Anxiety and stress supersede other causes of chest pain in young otherwise healthy patients with normal examination. This young man had been seeking medical attention for some time. In current times there is more emphasis on documentation. Unfortunately, this is at the cost of less time for history-taking and clinical examination. Additionally, due to the availability of multimodality imaging, clinical examination has become a fading skill. Our patient had a typical history and significantly loud systolic murmur. Though his final diagnosis of unicuspid aortic valve (UAV) is a very rare finding, his presenting signs and symptoms should have prompted early work up. This case illustrates the importance of a basic bedside examination in this high tech era.

\section{CASE PRESENTATION}

A 22-year-old otherwise healthy man was referred to our institution, with a history of progressively worsening chest pain. Initially, symptoms occurred only after strenuous activity but, recently, a normal to brisk walk would result in left-sided chest pain radiating to the neck and left shoulder with complete resolution of symptoms at rest. The patient did not have any coronary artery disease risk factors and led a healthy life style. He denied using tobacco, alcohol or recreational drugs. There was no history of dizziness syncope or presyncope. The patient denied any family history of sudden death at a young age. He outplayed his friends in field sports during most of his teenage years. He was not on any regular medication.

Physical examination revealed weak peripheral pulses. Heart rate was $68 \mathrm{bpm}$. Blood pressure was $110 / 70 \mathrm{~mm} \mathrm{Hg}$ in both arms. Body temperature and saturations were normal; there was no cyanosis or clubbing. Neck examination revealed diminished and delayed carotid upstroke. There was normal jugular venous pressure. The chest was clear to auscultation without any added sounds. Precordium was normal. A normal S1 with a soft S2 were audible. A 3/6 late peaking systolic murmur was best heard in the aortic area radiating to the neck. The murmur became somewhat softer with Valsalva manoeuvre. There was no radiofemoral delay. The rest of the clinical examination was within normal limits.

\section{INVESTIGATIONS}

Baseline blood tests revealed normal complete blood count. Metabolic panel, including electrolytes, lipids, liver and kidney function tests, was normal.

ECG: Normal sinus rhythm, normal intervals with voltage criteria for left ventricular hypertrophy.

Chest X-ray was normal. Transthoracic echocardiography showed left ventricular hypertrophy, with normal left ventricular function. Severe aortic stenosis was noted and the valve was suspicious for a unicuspid versus bicuspid valve. Other valves were normal.

Transoesophegeal echocardiography (figure 1A, B) and three-dimensional (3D) echocardiography (figure 2) confirmed the UAV with a normal ascending aorta. Coronary CT showed a normal ascending, arch and descending aorta. Coronary arteries were angiographically normal. Other associated congenital anomalies were excluded.

\section{DIFFERENTIAL DIAGNOSIS}

Angina with systolic murmur in young adults should raise the suspicion of dynamic or fixed left ventricular outflow tract obstruction. Hypertrophic obstructive cardiomyopathy, aortic valvulopathy from bicuspid, unicuspid and, rarely, rheumatic valve disease and sub or supra aortic membranes, should be excluded.

Angina without cardiac murmur in the young should prompt the physician to investigate for anomalous coronary arteries. Coronary aneurysm from Kawasaki disease may present with anginal symptoms. Aggressive atherosclerotic coronary artery disease may result from metabolic, lipid, glucose, steroid and autoimmune abnormalities.

\section{TREATMENT}

Prior to surgery, ample time was spent on patient education and evaluating his social support system. The patient was informed regarding life style 

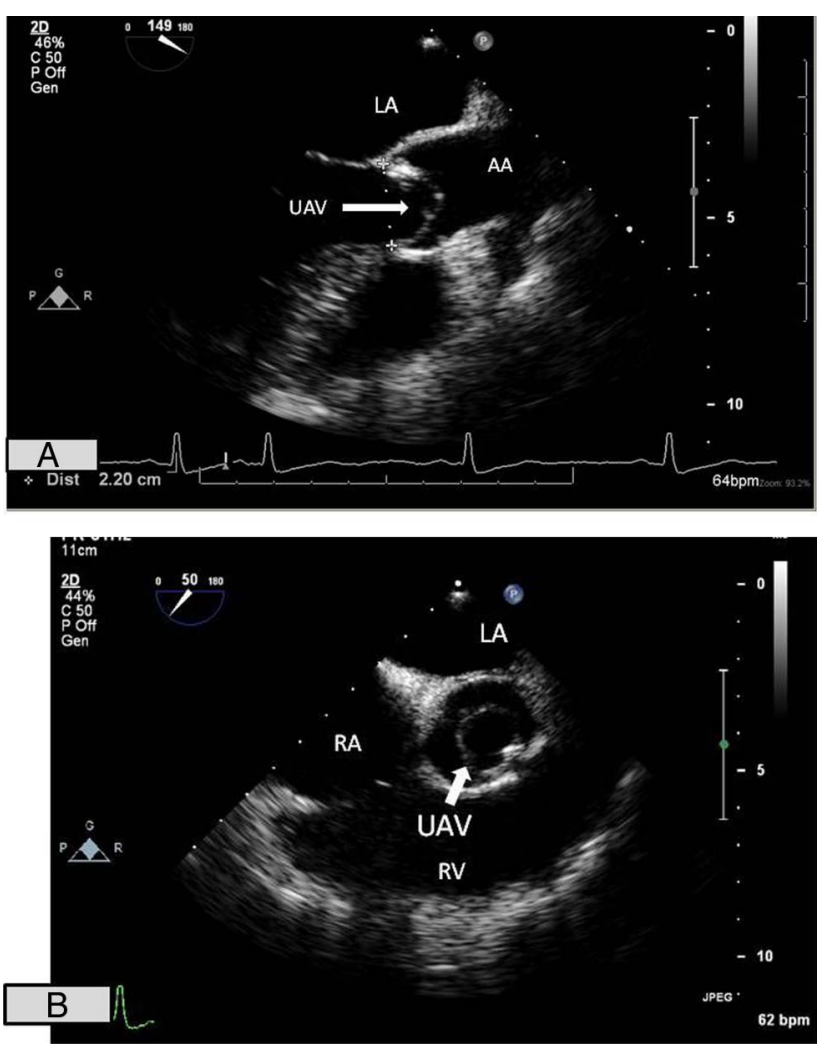

Figure 1 (A) Transoesophageal echocardiographic mid-oesophageal short axis view $\left(149^{\circ}\right)$. Unicuspid valve with eccentric valvular orifice. AA, ascending aorta; LA, left atrium; UAV, unicuspid aortic valve. (B) Transoesophageal echocardiographic mid-oesophageal short axis view $\left(50^{\circ}\right)$. Unicuspid valve with eccentric valvular orifice. $L A$, left atrium; $\mathrm{RA}$, right atrium; RV, right ventricle; UAV, unicuspid aortic valve.

changes, the importance of lifelong medication compliance and endocarditis prophylaxis. He successfully underwent mechanical aortic valve replacement surgery. The postoperative period was uneventful.

\section{OUTCOME AND FOLLOW-UP}

At 1-year follow-up, he remains asymptomatic and compliant with medical instructions. He is enjoying an active and healthy life style and remains a valuable member of the community.

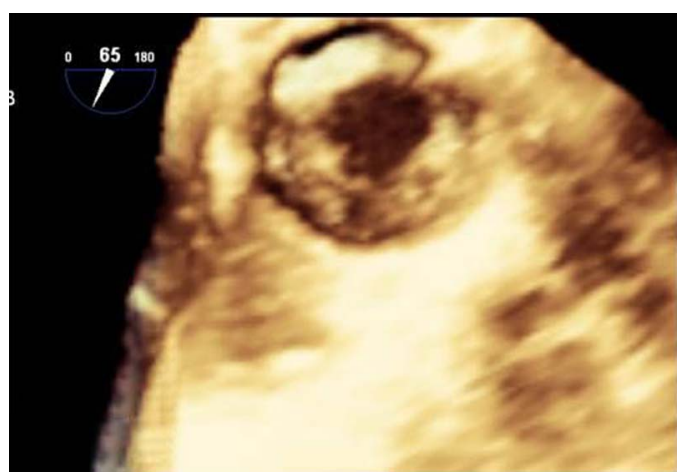

Figure 2 Three-dimensional transoesophageal echocardiographic mid-oesophageal short axis view $\left(65^{\circ}\right)$. Unicuspid valve with eccentric valvular orifice.

\section{DISCUSSION}

$\mathrm{UAV}$ is a rare congenital heart anomaly that results from the fusion of the three tubercles during embryonic life. It may occur alone or may be associated with other anomalies such as patent ductus arteriosis, aortic aneurysms and coarctation of the aorta. ${ }^{1}$ The reported incidence is about $0.02 \%$ in patients referred for echocardiography. ${ }^{2}$ A much higher incidence of $4-6 \%$ is observed in patients undergoing surgery for aortic stenosis. $^{3}$

Two types of UAV have been described. ${ }^{4}$ The acommissural type has a central pinhole-shaped opening and presents with symptoms that require intervention in infancy and childhood. ${ }^{5}$ In the unicommissural UAV, as in our patient, the valve has a slitlike opening. ${ }^{1}$ Symptoms usually develop in early to midadulthood. Aortic root dilation seems to be caused by medial changes in the aortic tissue. ${ }^{6}$ Aortopathy has a bimodal distribution, older patients without aortic root dilation, and younger with UAV having an aggressive form of aortic root dilation. ${ }^{7}$ Early valve dysfunction, pathological aortopathy and dystrophic calcification are common features in unicuspid and bicuspid valves.

Dyspnoea on exertion, chest pain and syncope are common to all stenotic aortic valves irrespective of the number of cusps. These symptoms develop and progress to necessitate surgery earlier in unicuspid, followed by bicuspid and lastly by tricuspid valves. ${ }^{8}$ UAVs are heavily calcified and weigh twice as much as stenotic tricuspid aortic valves. ${ }^{9}$ This calcification may affect the conduction system of the heart.

Diagnosis is usually established by transthoracic, transoesophageal and 3D echocardiography. ${ }^{10}$ Cardiac CT or Cardiac MR are vital to access cardiac and extracardiac associations with this congenital valve problem. ${ }^{11}{ }^{12}$ Treatment in adults is mostly aortic valve replacement. If aortopathy is found, aortic annulus, root and ascending aorta replacement is performed as well.

\section{Learning points}

- History taking and clinical examination still remain the most important steps in diagnosis and subsequent management of patients.

- Bicuspid aortic valve is a well-known entity. However, increased awareness of unicuspid aortic valve (UAV) disease with early presenting symptoms is essential. The diagnosis and management of each such reported case adds to our pool of knowledge.

- Non-invasive, multimodality cardiac imaging obviates the need for invasive angiogram.

- Patient education and strengthening of their social support system are of key importance in the management of young patients on lifelong medications.

Competing interests None declared.

Patient consent Obtained.

Provenance and peer review Not commissioned; externally peer reviewed.

\section{REFERENCES}

1 Mookadam F, Thota VR, Garcia-Lopez AM, et al. Unicuspid aortic valve in adults: a systematic review. J Heart Valve Dis 2010;19:79-85.

2 Novaro GM, Mishra M, Griffin BP. Incidence and echocardiographic features of congenital unicuspid aortic valve in adult population. $J$ Heart Valve Dis $2003 ; 12: 674-8$ 
3 Roberts WC, Ko JM. Frequency by decades of unicuspid, bicuspid, and tricuspid aortic valve in adults having isolated aortic valve replacement for aortic stenosis, with or without associated aortic regurgitation. Circulation 2005;111:920-5.

4 Anderson RH. Understanding the structure of the unicuspid and unicommissural aortic valve. J Heart Valve Dis 2003;12:670-3.

5 Moller JH, Nakib A, Eliot RS, et al. Symptomatic congenital aortic stenosis in the first year of life. J Pediatr 1966;69:728-34.

6 Butany J, Vaideeswar $P$, Dixit $V$, et al. Ascending aortic aneurysms in unicommissural aortic valve disease. Cardiovasc Pathol 2009;18:11-18.

7 Agnihotri AK, Desai SC, Lai YQ et al. Two distinct clinical presentations in adult unicuspid aortic valve. J Thorac Cardiovasc Surg 2006;131:1169-70.

8 Subramanian R, Olson LJ, Edwards WD. Surgical pathology of pure aortic stenosis: a study of 374 cases. Mayo Clin Proc 1984;59:683-90.
9 Roberts WC, Ko JM. Weights of operatively-excised stenotic unicuspid, bicuspid and tricuspid aortic valves and their relation to age, sex, body mass index, and presence or absence of concomitant coronary artery bypass grafting. Am J Cardiol 2003;92:1057-65.

10 Chu JW, Picard MH, Agnihotri AK, et al. Diagnosis of congential unicuspid aortic valve in adult population: the value and limitations of transesophaggeal echocardiography. Echocardiography 2010;27: 1107-12.

11 Gibbs WN, Hamman BL, Roberts WC, et al. Diagnosis of congential unicuspid aortic valve by 64 -slice cardiac computed tomography. Proc (Bayl Univ Med Cent) 2008;21:139.

12 Debl K, Djavidani B, Buchner $\mathrm{S}$, et al. Unicuspid aortic valve disease: a magnetic resonance imaging study. Rofo 2008;180:983-7.

Copyright 2015 BMJ Publishing Group. All rights reserved. For permission to reuse any of this content visit http://group.bmj.com/group/rights-licensing/permissions.

BMJ Case Report Fellows may re-use this article for personal use and teaching without any further permission.

Become a Fellow of BMJ Case Reports today and you can:

- Submit as many cases as you like

- Enjoy fast sympathetic peer review and rapid publication of accepted articles

- Access all the published articles

- Re-use any of the published material for personal use and teaching without further permission

For information on Institutional Fellowships contact consortiasales@bmjgroup.com

Visit casereports.bmj.com for more articles like this and to become a Fellow 